\title{
Tantangan Pendidikan Inklusi Dalam Mendidik Anak Berkebutuhan Khusus
}

\author{
Rizka Norsy Ramadhana \\ Program Studi Pendidikan Bahasa Inggris \\ Universitas Lambung Mangkurat \\ Email: $\underline{\text { rizkanorsy@gmail.com }}$
}

\begin{abstract}
Abstrak :
Pendidikan Inklusi merupakan salah satu program pemerintah dalam mewujudkan keadilan di bidang pendidikan. Pendidikan Inklusi menjadi salah satu bentuk perwujudan pemerataan pendidikan tanpa diskriminasi. Dalam pendidikan inklusi, anak berkebutuhan khusus (ABK) harus mendapatkan layanan pendidikan yang sama dengan anak normal di sekolah reguler. Untuk memperoleh data yang diperlukan, peneliti menggunakan studi literature. Metode penelitian ini menggunakan studi pustaka yang bersumber dari buku, jurnal dan lainnya. Dalam pelaksanaannya terdapat bebagai tantangan yang menjadi hambatan pendidikan inklusi. Tujuan penelitian ini untuk mengetahui tantangan yang dihadapi antara lain; kurangnya keterampilan dan sikap guru dalam menangani ABK, keterbatasan sarana dan prasarana serta rendahnya kesadaran orang tua dan masyarakat terhadap hak anak berkebutuhan khusus.

Kata Kunci : anak berkebutuhan khusus, pendidikan inklusi, tantangan penyelenggaraan pendidikan inklusi
\end{abstract}

\section{Abstract :}

Inclusive education is one of the government programs in realizing justice in the field of education. Inclusive education is a form of equal distribution of education without discrimination. In inclusive education, children with special needs (ABK) must get the same educational services as normal children in regular schools. To obtain the necessary data, researchers used literature studies. This research method uses literature study sourced from books, journals and others. In its implementation, there are various challenges that become obstacles to inclusive education. The purpose of this study was to determine the challenges faced, among others; lack of skills and attitudes of teachers in dealing with children with special needs, limited facilities and infrastructure and low awareness of parents and the community towards the rights of children with special needs.

Keywords: children with special needs, inclusive education, challenges in implementing inclusive education 


\section{PENDAHULUAN :}

Berdasarkan UU No. 20 tahun 2003 Pasal 32 ayat 1 yang bunyinya "pendidikan khusus merupakan pendidikan bagi peserta didik yang memiliki tingkat kesulitan dalam mengikuti proses pembelajaran karena kelainan fisik, emosional, mental, sosial dan / atau memiliki potensi kecerdasan dan bakat istimewa". Pendidikan merupakan salah satu bentuk usaha untuk meningkatkan mutu sumber daya manusia. Di Indonesia sendiri praktik penyelenggaraan pendidikan bagi anak berkebutuhan khusus telah diselenggarakan oleh Lembagalembaga Sosial Masyarakat (LSM) maupun kelompok-kelompok keagamaan sejak 1901. Pendidikan sangat dibutuhkan bagi anak-anak untuk mencapai kesejahteraan sosial dan hidupnya. Semua anak berhak mendapatkan pendidikan tak terkecuali anak-anak yang segi fisik maupun mental nya kurang atau berbeda dari anak normal lainnya. Pemerintah telah bertindak menyediakan fasilitas pendidikan khusus bagi para anak berkebutuhan khusus (ABK). Sesuai dengan Undang-Undang Nomor 20 Tahun 2003 pada Pasal 5 Ayat 1, bahwa setiap warga negara mempunyai hak yang sama untuk memperoleh pendidikan yang bermutu. Pasal 32 ayat 1 UU No. 20 tahun 2003, pendidikan khusus merupakan pendidikan bagi peserta didik yang memiliki tingkat kesulitan dalam mengikuti proses pembelajaran karena kelainan fisik, emosional, mental, sosial dan / atau memiliki potensi kecerdasan dan bakat istimewa. Dilanjutkan pada ayat 2 , pendidikan layanan khusus merupakan pendidikan bagi peserta didik di daerah terpencil atau keterbelakang, masyarakat adat yang terpencil, dan / atau yang mengalami bencana alam, bencana sosial dan tidak mampu dari segi ekonomi.

Dalam perwujudan dari pasal diatas pemerintah telah membentuk Sekolah Luar Biasa (SLB). Akan tetapi SLB dianggap sebagai tembok pemisah antara anak-anak pada umumnya dan anak yang berkebutuhan khusus. Dalam mengatasi masalah ini perlu disediakan berbagai layanan pendidikan yang sesuai dengan anak berkebutuhan khusus, baik dari sarana dan prasarana, guru, serta lingkungan. Bagi anak berkebutuhan khusus, pendidikan inklusi memiliki peran memberi kesempatan mereka untuk belajar bersama siswa-siswa lain seusianya yang tidak berkebutuhan khusus. Sekolah inklusi merupakan sekolah yang dianggap tepat bagi anak berkebutuhan khusus. Pratiwi dalam (Ilahi, 2013: 25), menjelaskan bahwa sekolah inklusi adalah sekolah regular yang disesuaikan dengan kebutuhan anak yang memiliki kelainan dan memiliki potensi kecerdasan dan bakat 
istimewa pada satu kesatuan yang sistemik. Sekolah inklusi juga memberikan kesempatan bagi anak berkebutuhan khusus agar dapat mengenyam pendidikan yang adil.

Agar terciptanya keberlangsungan pendidikan inklusi perlu adanya faktor pendukung yang paling penting yaitu partisipasi dari semua komponen didalamnya meliputi kepala sekolah, guru, orang tua, masyarakat, bahkan sarana dan prasarana yang ada di sekolah seperti ketersediaan petugas kesehatan dan lainnya. Kolaborasi antara sekolah dan komunitas juga menjadi kunci keberhasilan pendidikan inklusif (Amka, 2019). Namun dalam pelaksanaannya, pendidikan inklusi tidak berjalan lancar seperti yang di bayangkan. Terdapat berbagai tantangan dan hambatan yang harus dihadapi baik dari dalam maupun luar sekolah. Amka (dalam Ainscow dan Haile-Giorgis (1999), menjelaskan bahwa ketika orang mendorong langkah menuju praktik pendidikan yang lebih inklusif, mereka juga harus realistis dengan hambatan yang akan dihadapi. Tantangan dan hambatannya berasal dari siswa, guru, orang tua, masyarakat, sekolah, dll.

\section{METODE :}

Pada penelitian ini peneliti menggunakan pendekatan berupa penelitian Studi Kepustakaan (Library
Research). Sarwono (2006) menjelaskan Studi kepustakaan juga bisa dilakukan dengan mempelajari beberbagai buku referensi serta hasil penelitian sebelumnya yang sejenis yang berguna untuk mendapatkan landasan teori mengenai masalah yang akan diteliti. Selain itu menurut Nazir (2003 : 111), Studi kepustakaan adalah teknik pengumpulan data dengan mengadakan studi penelaahan terhadap buku- buku, litertur-literatur, catatan-catatan, dan laporan-laporan yang ada hubungannya dengan masalah yang dipecahkan. Peneliti melakukan penelitian teoritis terkait topik penelitian dan mengumpulkan informasi sebanyakbanyaknya dari literatur yang relevan. Jadi bisa disimpulkan bahwa penelitian menggunakan studi pustaka digunakan untuk mengumpulkan data dan informasi yang bisa didapatkan dari buku, jurnal, karya tulis, website, berita, dan sumber lainnya.

\section{HASIL DAN PEMBAHASAN}

1. Latar Belakang Penyeleggaraan Sekolah Inklusi

Sesuai dengan Pasal 31 ayat (1) Undang-Undang Dasar Negara Republik Indonesia Tahun 1945 menyebutkan bahwa setiap warga Negara berhak mendapat pendidikan, dan ayat menegaskan bahwa Pemerintah mengusahakan dan 


\begin{tabular}{|c|c|}
\hline $\begin{array}{l}\text { menyelenggarakan suatu system } \\
\text { pendidikan nasional yang }\end{array}$ & $\begin{array}{lrr}\text { sama untuk memperoleh } \\
\text { pendidikan yang } & \text { bermutu. }\end{array}$ \\
\hline meningkatkan & Berdasarkan UU No. 20 tahun \\
\hline ketakwaan serta akhlak mulia & 2003 Pasal 32 ayat 1 , pendidikan \\
\hline dalam rangka mencerdaskan & khusus merupakan pendidikan bagi \\
\hline kehidupan bangsa sesuai dengan & peserta didik yang memiliki tingkat \\
\hline undang-undang. Dalam pasal & kesulitan dalam mengikuti proses \\
\hline tersebut disebutkan "setiap warga & pembelajaran karena kelainan fisik, \\
\hline negara" berhak mendapatkan & emosional, mental, sosial dan / atau \\
\hline pendidikan, dengan kata lain anak & memiliki potensi kecerdasan dan \\
\hline berkebutuhan khusus termasuk & bakat istimewa. Pada ayat 2, \\
\hline didalamnya. Pendidikan & dijelaskan \\
\hline kebutuhan bagi & merupakan \\
\hline manusia. Selain anak yang normal, & pendidikan bagi peserta didik di \\
\hline anak berkebutuhan khusus juga & terpencil \\
\hline membutuhkan pendidikan yang & keterbelakang, masyarakat adat \\
\hline sama. Berdasarkan Karakter yang & yang terpencil, dan / atau yang \\
\hline berlandaskan falsafah Pancasila & mengalami bencana alam, bencana \\
\hline dikutip dari buku Filsafah & sosial dan tidak mampu dari segi \\
\hline Pendidikan (Amka, 2019), & ekonomi. \\
\hline karakter kemanusiaan seseorang & Mengutip dari \\
\hline tercermin antara lain dalam & (2015), hak atas pendidikan juga \\
\hline pengakuan atas persamaan derajat, & termasuk dalam Deklarasi Umum \\
\hline hak, dan kewajiban; saling & Hak Asasi Manusia 1948 (The \\
\hline mencintai; memiliki tenggang rasa; & 1948 Universal Declaration of \\
\hline tidak bertindak semena-mena & Human Right), yang kemudian \\
\hline terhadap orang lain; gemar & diperbarui pada Konferensi Dunia \\
\hline melakukan kegiatan kemanusiaan; & 1990 tentang Pendidikan untuk \\
\hline serta menjunjung tinggi nilai & Semua $\quad$ The \\
\hline kemanusiaan. & Conference on Education for All), \\
\hline Sesuai dengan Undang- & tujuannya adalah untuk \\
\hline Undang Nomor 20 Tahun 2003 & memastikan bahwa hak-hak ini \\
\hline pada Pasal 5 Ayat 1 , bahwa s & untuk semua orang, \\
\hline sa negara mempun & terlepas dari 1 \\
\hline
\end{tabular}


Berdasarkan hak hak tersebut, anak berkebutuhan khusus wajib mendapatkan hak untuk mendapatkan pendidikan. Seperti yang dijelaskan Amka (2017) dengan menyatukan ke dalam ruang kelas yang sama, akan memberikan pengertian kepada peserta didik bahwa dalam kehidupan akan ditemuai banyak sekali perbedaan. Perbedaanperbedaan itu diharapkan menjadi sebuah kenyataan yang harus dihadapi dan dihormati, bukan dijadikan sebagai hambatan. Anak berkebutuhan kusus harus mendapatkan hak yang sama dengan anak yang normal. Hal ini sesuai dengan program pemerintah yang bernama pendidikan inklusi.

2. Tantangan Penyelenggaraan Pendidikan Inklusi

Dalam penyelenggaraan pendidikan inklusi tidak semudah membalikan telapak tangan. Terdapat banyak tantangan yang di hadapi baik dari dalam maupun luar sekolah. Tantangan ini akan menjadi hambatan dalam terciptanya pendidikan inklusi yang baik. Hambatan yang pertama adalah dari tenaga pengajar atau guru. Guru memiliki peranan penting dalam mendidik di pendidkan inklusi. Pendidikan inklusif yang terjadi di Indonesia masih mengalami hambatan, hambatan yang terjadi selama ini adalah kurangnya pengetahuan guru tentang anak berkebutuhan khusus, minimnya keterampilan guru dalam menangani ABK dan sikap guru terhadap $\mathrm{ABK}$ yang dilihat masih memandang sebelah mata (Juwono \& Kumara, 2011). Sikap guru terhadap pendidikan inklusif didefinisikan sebagai kecenderungan untuk berespon secara kognitif, afektif, dan konatif terhadap pendidikan inklusif (Mahat, 2008). Winarti (2015) menyebutkan kondisi guru belum didukung dengan kualitas guru yang memadai. Keberadaan guru khusus masih dinilai belum sensitif dan proaktif terhadap permasalahan yang dihadapi ABK. Winarti juga menyebutkan bahwa guru belum didukung dengan kejelasan aturan tentang peran, tugas dan tanggung jawab masing-masing guru. Pelaksanaan tugas belum disertai dengan diskusi rutin, tersedianya model kolaborasi sebagai panduan, serta dukungan anggaran yang memadai (Winarti, 2015).

Selain guru, dalam penyelenggaraan pendidikan 
inklusi dibutuhkan sarana dan prasarana yang bai. Tapi dalam kenyataannya masih terbatasnya sarana dan prasarana tersebut. Memang dalam penyelenggaraan pendidikan inklusi membutuhkan sarana dan prasarana yang banyak. Hal ini karena sekolah harus menyesuaikan dengan berbagai jenis kebutuhan anak berkebutuhan khusus yang berbeda-beda seperti alat bantu dengar, buku timbul, dan sebagainya yang harus disesuaikan dengan kondisi ABK. Dengan keterbatasaan ini mempengaruhi kurangnya sekolah dalam pelayanan terhadap anak berkebutuhan khusus. Masalah utama minimnya sarana dan prasarana yang dimiliki adalah faktor biaya (Pratiwi, 2015).

Rendahnya kesadaran orang tua dan masyarakat terhadap hak anak berkebutuhan khusus menjadi tantangan yang harus dihadapi dalam penyelenggaraan pendidikan inklusi. Amka (dalam Holden 1995) menyebutkan Sikap dan perilaku orang tua memengaruhi perilaku anak-anak mereka, yang kemudian dibawa ke kehidupan selanjutnya. Teori ini menunjukkan bahwa orang tua yang tidak mendukung pendidikan inklusif dapat memengaruhi secara negatif pembentukan sikap dan perilaku anak mereka (Amka, 2019). Apabila orang tua mendukung penuh anaknya yang berkebutuhan khusus, ini sangat memungkinkan anak tersebut mencapai potensi maksimalnya. Danielsen, Samdal, Hetland dan Wold (2009) menyatakan Dukungan dari ibu dapat memunculkan perasaan berharga pada anak, sementara dukungan dari ayah dapat mengembangkan kompetensi anak.

Selain orang tua, peranan masyarakat juga penting dalam menangani anak berkebutuhan khusus. Orang tua dan masyarakat adalah lingkungan terdekat yang memliki peranan penting. Sikap menerima dan mendukung kekurangan anak dari orang tua dan masyarakat dapat mendorong anak lebih dalam mengembangkan potensinya. Jika orang tua dan masyarakat tidak menerima dan mendukung maka kemajuan anak berkebutuhan khusus akan semakin terhambat. Anak berkebutuhan khusus akan cenderung malu dan cemas untuk memulai melakukan sesuatu.

Sayangnya dikeadaan nyata saat ini, orang tua masih ragu 
bahkan takut untuk menyekolahkan anaknya ke sekolah reguler. Alasannya mulai dari takut anak tidak mampu, takut ada diskriminasi, dan lainnya. Selain itu masyarakat juga kurang peduli tentang keberadaan anak berkebutuhan khusus dan terkesan membedakan antara anak normal dan $\mathrm{ABK}$.

3. Sikap Terhadap Tantangan Pendidikan Inklusi

Pengembangan kemampuan dan model mengajar guru diperlukan untuk mendukung pendidikan inklusi. Pelatihan mengenai pendidikan inklusif pada guru-guru juga merupakan faktor yang dapat memengaruhi sikap pada pendidikan inklusif. Hasil penelitian ini adalah guru yang pernah mengikuti pelatihan pendidikan inklusif memiliki sikap positif yang tinggi dibandingkan guru-guru yang tidak pernah mengikuti pelatihan (Dewi, Tiatri dan Mularsih, 2020). Dewi, Tiatri dan Mularsih (dalam Subban dan Sharma, 2006) melaporkan bahwa guru yang pernah mengikuti pelatihan tentang mengajar peserta didik berkebutuhan khusus memiliki sikap yang lebih positif dibandingkan guru yang tidak mengikuti pelatihan.

Keterbatasan sarana dan prasarana yang dihadapi sekolah dalam mewujudkan pendidikan inklui yang baik. Hal ini merupakan tantangan bagi pemerintah untuk memberikan bantuan berkaitan dengan fasilitas untuk sekolah inklusi (Konza, 2008). Pemerintah juga harus menyiapkan dana untuk sarana dan prasarana di sekolah reguler untuk anak berkebutuhan khusus. Pratiwi (2015), menyatakan kepala sekolah bisa membuat proposal pengajuan dana kepada pemerintah yang terkait. Komunikasi yang baik antara sekolah dan pemerintah ini diharapkan berdampak positif bagi kemajuan penyelenggaraan sekolah inklusi. Sehingga anak berkebutuhan khusus mendapatkan pelayanan yang maksimal.

Untuk menyadarkan orang tua dan masyarakat diperlukan peranan sekolah dan lembaga lembaga terkait. Orang tua dan masyarakat pelu diberikan wawasan tentang hak seriap anak dalam belajar, termasuk anak berkebutuhan khusus. Amka (2019) menyatakan bahwa sikap para orang tua berubah setelah 
mendapatkan sosialisasi dari pihak sekolah tentang pendidikan inklusif dan telah memahami prinsip keragaman kebutuhan belajar anak. Hal ini diharapkan dapat merubah pandangan masyarakat terhadap pendidikan yang adil untuk anak berkebutuhan khusus.

\section{KESIMPULAN}

Anak berkebutuhan khusus juga memiliki hak yang sama dengan anak normal. Sesuai dengan Undang-Undang Nomor 20 Tahun 2003 pada Pasal 5 Ayat 1, bahwa setiap warga negara mempunyai hak yang sama untuk memperoleh pendidikan yang bermutu. Anak berkebutuhan khusus wajib mendapatkan hak untuk mendapatkan pendidikan yang layak tanpa adanya diskriminasi. Pendidikan inklusi berperan sebagai pembentuk persamaan hak memperoleh pendidikan yang sama terhadap semua warga negara. Anak berkebutuhan khusus bisa sekolah bersama anak yang normal di sekolah reguler untuk mendapatkan penidikan yang berkualitas.

Dalam pendidikan inklusi terdapat berbagai tantangan yang menjadi

\section{REFERENSI}

Amka, (2019), Buku Ajar Filsafat Pendidikan, Gagasan Konsep, Teori dan Analisis Filosofis hambatan dalam pelaksanaannya. Kurangnya keterampilan dan sikap guru dalam menangani $\mathrm{ABK}$ padahal guru adalah elemen penting dalam pendidikan. Selain itu minimnya biaya mengakibatkan keterbatasan sarana dan prasarana di sekolah reguler. Rendahnya kesadaran orang tua dan masyarakat terhadap hak anak berkebutuhan khusus mengakibatkan rasa malu dan cemas $\mathrm{ABK}$ dalam mengembangkan potensinya.

Pengembangan kemampuan dan model mengajar guru diperlukan untuk mendukung pendidikan inklusi. Pelatihan mengenai pendidikan inklusif pada guruguru juga merupakan faktor yang dapat memengaruhi sikap pada pendidikan inklusif. Dukungan dana dari pemerintah sagatlah penting, sekolah harus aktif dalam pengajuan proposal agar sarana dan prasarana untuk $\mathrm{ABK}$ bisa terpenuhi. Peranan sekolah dan lembaga lembaga terkait untuk memberikan wawasan terhadap orang tua dan masyarakat sangat dibutuhkan. Dengan melakukan sosialisasi, diharapkan dapat merubah pandangan masyarakat terhadap pendidikan yang adil untuk anak berkebutuhan khusus.

Mengenai Sistem Pendidikan. Nizamia Learning Center, Sidoarjo. Amka, A (2019). Sikap Orang Tua Terhadap Pendidikan Inklusif, 
Madrosatuna: Journal of Islamic

Elementary School, Vol. 1 (1). 15-

27.

doi:

10.21070/madrosatuna.v3i1.2068

Amka, A. (2019). Pendidikan Inklusif Bagi

Siswa Berkebutuhan Khusus di

Kalimantan Selatan. Jurnal

Pendidikan Dan Kebudayaan, 4(1), $86-101$.

Amka, A. (2017). Implementasi Pendidikan Karakter Inklusi Bagi Anak Berkebutuhan Khusus Di Sekolah Reguler, Madrosatuna: Journal of Islamic Elementary School, Vol. 1 (1). 1-12. doi: 10.21070/madrosatuna.v1i1.1206

Budianto, (2007). Pengantar Pendidikan Inklusif. Prenadamedia Goup, Jakarta.

Danielsen, A. G., Samdal, O., Hetland, J., \& Wold, B. (2009). School-related social support and students' perceived life satisfaction. The Journal of educational research, 102(4), 303-320.

Dewi, T. T. U., Tiatri, S., \& Mularsih, H. (2020). PERAN PENGETAHUAN AWAL TENTANG ANAK BERKEBUTUHAN KHUSUS DAN EFIKASI GURU TERHADAP SIKAP GURU PADA PENDIDIKAN INKLUSIF. Jurnal Muara Ilmu
Sosial, Humaniora, dan Seni, 4(2), 304-314.

Juwono, I. D \& Kumara, A. (2011). Pelatihan Penyusunan Rancangan Pembelajaran pada Guru Sekolah Inklusi. Studi Kasus Pada SD "X" di Yogyakarta.

Kementerian Pendidikan Nasional. (2003). Undang-undang No. 20/2003 tentang system pendidikan nasional. Jakarta: Kementrian Pendidikan Nasional

Konza, D. (2008). Inclusion of students with disabilities in new times: responding to the challenge.

Mahat, M. (2008). The Development Of A Psychometrically-Sound Instrument To Measure Theacher's Multidimensional Attitudes Toward Inclusive Education. International Journal Of Special Education, 23(1)

Palmer, D. S., K. Fuller, T. Arora, and M. Nelson. 2001. "Taking Sides: Parent Views on Inclusion for Their Children with Severe Disabilities." Exceptional Children 67: 467-484.

Pratiwi, J. C. (2015, November). Sekolah inklusi untuk anak berkebutuhan khusus: tanggapan terhadap tantangan kedepannya. In Seminar Nasional Ilmu Pendidikan UNS 2015. Sebelas Maret University. 
Sari, M., \& Asmendri, A. (2020).

Penelitian Kepustakaan (Library

Research) dalam Penelitian

Pendidikan IPA. NATURAL

SCIENCE: Jurnal Penelitian

Bidang IPA dan Pendidikan

IPA, 6(1), 41-53. 